Received: 3 May 2017

Accepted: 13 July 2017

Published online: 15 August 2017
CIENTIFIC REP

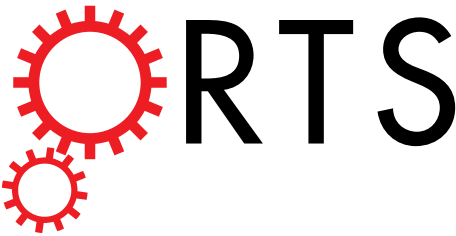

\section{OPEN An Evaluation of the in vivo Safety of Nonporous Silica Nanoparticles: Ocular Topical Administration versus Oral Administration}

\author{
Martha Kim ${ }^{1}$, Joo-Hee Park ${ }^{1}{ }^{1}$, Hyejoong Jeong ${ }^{2}$, Jinkee Hong ${ }^{2}$, Woo Sung Choi ${ }^{3}$, Byung-Han \\ Lee $^{3} \&$ ChoulYong Park ${ }^{1}$
}

Nonporous silica nanoparticles (SiNPs) have potential as promising carriers for ophthalmic drugs. However, the in vivo safety of ocular topical SiNPs remains unclear. This study investigated the in vivo safety of oral and ocular topical applications of $100 \mathrm{~nm}$-sized SiNPs in Sprague-Dawley rats. The rats were divided into the following four groups: low-dose oral administration (total $100 \mathrm{mg} / \mathrm{kg}$ of SiNPs mixed with food for one week), high-dose oral administration (total $1000 \mathrm{mg} / \mathrm{kg}$ of SiNPs mixed with food for one week), ocular topical administration $(10 \mathrm{mg} / \mathrm{ml}$ concentration, one drop, applied to the right eyes four times a day for one month), or a negative control (no SiNP treatment). The rats were observed for 12 weeks to investigate any signs of general or ocular toxicity. During the observation period, no differences were observed in the body weights, food and water intakes, behaviors and abnormal symptoms of the four groups. No animal deaths occurred. After 12 weeks, hematologic, blood biochemical parameters and ophthalmic examinations revealed no abnormal findings in any of the animals. The lack of toxicity of the SiNPs was further verified in autopsy findings of brain, liver, lung, spleen, heart, kidneys, intestine, eyeballs, and ovaries or testes.

Recent advances in particle engineering technology have expanded the applications of nanoparticles (NPs), which can now serve as novel drug carriers. Nonporous silica NPs (SiNPs), which are commonly used as additives in cosmetics, printer toners, packaging, and imaging, represent promising drug carrier systems ${ }^{1}$. The stable chemical structure, large surface to volume ratios, ease of surface modification, and tolerable biodegradability of SiNPs greatly increase their attractiveness in biological applications as nanocarriers ${ }^{1}$.

As is well known, ocular drug penetration is difficult due to extrinsic and intrinsic ocular barriers, such as the tear film, mucus barrier, tight junction of the corneal epithelium, hydrophilicity of the corneal epithelium, and hydrophobicity of the corneal stroma ${ }^{2}$. Therefore, nano-based drug carrier systems, such as SiNPs, are a promising field of research for efficient ocular drug deliver ${ }^{3,4}$. Several recent reports described successful intraocular drug or gene delivery via various NPs, further increasing expectations regarding their potential ${ }^{5-11}$.

Despite the potential of NPs, such as SiNPs, a major concern is their safety in medical applications ${ }^{12,13}$. Research has shown that inhalation of some SiNPs can damage pulmonary cells via the induction of oxidative stress $^{14}$. Disturbance of calcium homeostasis of neuronal cells after SiNP exposure has also been previously reported ${ }^{15}$. Concerns about the intestinal toxicity and genotoxicity of SiNPs have also been raised ${ }^{16}$. Nevertheless, recent research pointed to the safety of SiNPs. For example, Ryu et al. ${ }^{17}$ reported that SiNPs had no toxic effects, including no such effects on internal organs, after dermal topical application of SiNPs for 90 days. In another report, SiNPs elicited only minimal biological toxicity in intestinal cells compared to marked toxicity caused by zinc oxide NPs ${ }^{18}$. Previously, our group reported the in vitro safety of SiNPs on cultured human corneal epithelial cells and keratocytes ${ }^{19}, 20$. In our previous study, various sized SiNPs $(50,100$, and $150 \mathrm{~nm})$ did not result in any significant impairment of cellular viability after exposure for $24 \mathrm{~h}$ to concentrations up to $100 \mu \mathrm{g} / \mathrm{ml}$. It is likely that the nanotoxicity of SiNPs are cell-type dependent ${ }^{13}$. Different types of cells are exposed to SiNPs, depending

${ }^{1}$ Department of Ophthalmology, Dongguk University, Ilsan Hospital, Goyang, South Korea. ${ }^{2}$ School of Chemical Engineering and Material Science, Chung-Ang University, Seoul, South Korea. ${ }^{3}$ Laboratory Animal Center, Osong Medical Innovation Foundation, Cheongju, South Korea. Correspondence and requests for materials should be addressed to C.Y.P. (email: oph0112@gmail.com) 


\begin{tabular}{|l|l|l|l|}
\hline Group & Route & Dose & $\begin{array}{l}\text { Number of } \\
\text { animals }\end{array}$ \\
\hline G1 (Control) & & & $\begin{array}{l}5 \text { males and 5 } \\
\text { females }\end{array}$ \\
\hline G2 & oral & $100 \mathrm{mg} / \mathrm{kg}$ & $\begin{array}{l}5 \text { males and 5 } \\
\text { females }\end{array}$ \\
\hline G3 & oral & $1000 \mathrm{mg} / \mathrm{kg}$ & $\begin{array}{l}5 \text { males and 5 } \\
\text { females }\end{array}$ \\
\hline G4 & topical & $\begin{array}{l}0.1 \mathrm{ml} \mathrm{q.i.d} \mathrm{for} \mathrm{1} \\
\text { month }\end{array}$ & $\begin{array}{l}5 \text { males and 5 } \\
\text { females }\end{array}$ \\
\hline
\end{tabular}

Table 1. Groups, route of administration and dose levels of silica nanoparticles.

\begin{tabular}{|c|c|c|c|c|c|c|c|c|c|c|c|c|c|c|}
\hline & & 0 week & 1 week & 2 week & 3 week & 4 week & 5 week & 6 week & 7 week & 8 week & 9 week & $\begin{array}{l}10 \\
\text { week }\end{array}$ & $\begin{array}{l}11 \\
\text { week }\end{array}$ & $\begin{array}{l}12 \\
\text { week }\end{array}$ \\
\hline \multirow{3}{*}{ G1 } & Mean & 205.9 & 234.9 & 255.3 & \begin{tabular}{|l|}
273.7 \\
\end{tabular} & 287.1 & 288.9 & 301.7 & 312.9 & 323.3 & \begin{tabular}{|l|}
314.7 \\
\end{tabular} & 328.1 & 333.7 & 337.1 \\
\hline & SD & 38.5 & 45.5 & 56.0 & 63.5 & \begin{tabular}{|l|}
67.9 \\
\end{tabular} & 70.9 & \begin{tabular}{|l|}
71.4 \\
\end{tabular} & \begin{tabular}{|l|l|}
75.1 \\
\end{tabular} & 87.4 & \begin{tabular}{|l|l|}
78.8 \\
\end{tabular} & 83.9 & 86.7 & 89.0 \\
\hline & $\mathrm{N}$ & 10 & 10 & 10 & 10 & 10 & 10 & 10 & 10 & 10 & 10 & 10 & 10 & 10 \\
\hline \multirow{3}{*}{ G2 } & Mean & 204.6 & 241.0 & 262.6 & 281.7 & \begin{tabular}{|l|}
297.8 \\
\end{tabular} & 301.6 & 310.7 & 322.8 & 332.7 & 346.3 & 345.0 & 347.0 & 351.0 \\
\hline & SD & 39.2 & 56.6 & 65.0 & \begin{tabular}{|l|}
75.1 \\
\end{tabular} & 81.5 & \begin{tabular}{|l|}
83.8 \\
\end{tabular} & \begin{tabular}{|l|}
85.7 \\
\end{tabular} & \begin{tabular}{|l|}
90.4 \\
\end{tabular} & 91.8 & \begin{tabular}{|l|l|}
103.9 \\
\end{tabular} & 96.4 & 99.2 & 103.7 \\
\hline & $\mathrm{N}$ & 10 & 10 & 10 & 10 & 10 & 10 & 10 & 10 & 10 & 10 & 10 & 10 & 10 \\
\hline \multirow{3}{*}{ G3 } & Mean & 204.9 & 235.8 & 261.0 & 276.6 & 293.9 & 296.2 & \begin{tabular}{|l|}
311.4 \\
\end{tabular} & 320.4 & 327.0 & \begin{tabular}{|l|}
328.9 \\
\end{tabular} & 339.2 & 345.0 & 347.7 \\
\hline & SD & 39.1 & 50.3 & 59.2 & \begin{tabular}{|l|}
70.4 \\
\end{tabular} & \begin{tabular}{|l|l|}
76.1 \\
\end{tabular} & \begin{tabular}{|l|}
79.3 \\
\end{tabular} & \begin{tabular}{|l|}
78.9 \\
\end{tabular} & \begin{tabular}{|l|l|}
86.9 \\
\end{tabular} & 89.5 & \begin{tabular}{|l|l}
92.1 \\
\end{tabular} & 97.7 & 99.4 & 103.8 \\
\hline & $\mathrm{N}$ & 10 & 10 & 10 & 10 & 10 & 10 & 10 & 10 & 10 & 10 & 10 & 10 & 10 \\
\hline \multirow{3}{*}{ G4 } & Mean & 205.2 & 228.7 & 243.9 & 263.2 & 277.3 & \begin{tabular}{|l|}
287.9 \\
\end{tabular} & \begin{tabular}{|l|}
306.0 \\
\end{tabular} & 314.6 & 327.7 & \begin{tabular}{|l|}
323.1 \\
\end{tabular} & 331.9 & 337.4 & 342.7 \\
\hline & SD & 38.9 & \begin{tabular}{|l|}
46.3 \\
\end{tabular} & 50.1 & 54.4 & \begin{tabular}{|l|l}
63.1 \\
\end{tabular} & \begin{tabular}{|l|}
65.9 \\
\end{tabular} & 65.5 & \begin{tabular}{|l}
75.4 \\
\end{tabular} & 77.5 & \begin{tabular}{|l|}
81.0 \\
\end{tabular} & 83.3 & 87.9 & 89.3 \\
\hline & $\mathrm{N}$ & 10 & 10 & 10 & 10 & 10 & 10 & 10 & 10 & 10 & 10 & 10 & 10 & 10 \\
\hline
\end{tabular}

Table 2. Body weight (gram) changes of rats after SiNPs application up to 12 weeks. G: group, SD: standard deviation, $\mathrm{N}$ : number.

on the route of SiNP administration. Therefore, independent evaluations of the nanotoxicity of ocular topical administration of SiNPs are necessary to resolve whether SiNPs are safe for ophthalmic uses.

The current study investigated the in vivo effects of oral and ocular topical SiNPs in rats over a 12-week period. General toxicity-related effects (e.g., changes in body weight and food and water intake) of the SiNPs, as well as specific effects on hematologic parameters, biochemical parameters, and vital organs, including eyeballs, were studied.

\section{Results}

Clinical observations. The rats were divided into four groups ( $n=10$ each): control (Group 1), low-dose oral intake (Group 2), high-dose oral intake (Group 3), and topical administration (Group 4). Each group contained an equal number of males and females (Table 1 ).

Body weight, food and water intake, behaviors and abnormal symptoms (such as hyper/hypo-activity, abnormal breathing, abnormal locomotion, lethargy, paresis, paralysis, tremor, ruffled fur and eye discharge) were observed over a 12-week period after the administration of the SiNPs. No deaths occurred in any of the animal groups. As compared with the untreated controls, none of the groups showed body weight loss, differences in food and water intake, abnormal behaviors, or general abnormal symptoms (Table 2) (Fig. 1).

Hematologic and biochemical examinations. The results of the hematologic and biochemical examinations 12 weeks after the application of the SiNPs are shown in Tables 1,2 and 3. There were no differences in the hematologic parameters of the oral intake groups (Groups 2 and 3). However, as compared to the control group (Group 1), there was a significant decrease in the mean platelet volume in Group 2. There were no differences in the hematologic parameters of the topical administration group (Group 4) compared to those of the oral intake groups. However, the mean platelet count $(P<0.01)$ and plateletcrit level $(P<0.05)$ of the topical administration group were significantly decreased compared to those of the control group (Table 3 ). There were no between-group differences in the differential count of white blood cells and reticulocytes (Table 4). Despite some significant differences between the groups, all the hematologic parameters were within normal ranges.

Table 5 shows the biochemical findings 12 weeks after the treatments. In Group 2, gamma glutamyl transpeptidase (GGT), lactate dehydrogenase, creatinine kinase, and creatinine values were significantly decreased compared to those of the control group. In Group 3, GGT, total protein, albumin, and blood urea nitrogen values were significantly increased compared to those of the control group. As compared to those of the controls, the total protein, albumin, blood urea nitrogen, and low-density lipoprotein cholesterol values of Group 4 were also significantly increased. All the biochemical parameters were within normal ranges, despite statistically significant differences between the groups. 


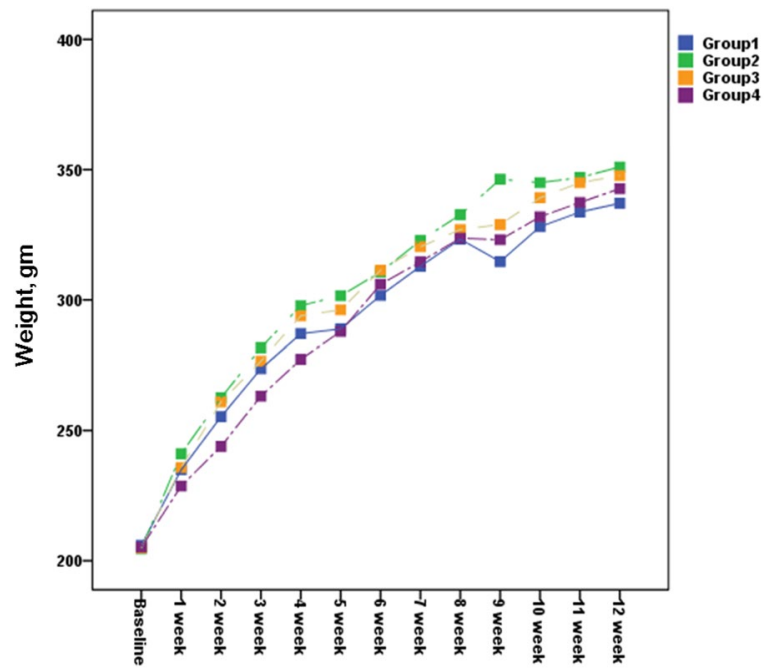

Figure 1. Body weight of the rats following the SiNP applications. There was no statistically significant difference in the body weights of the different groups (Group 1, control; Group 2, oral intake, $100 \mathrm{mg} / \mathrm{kg}$; Group 3, oral intake, $1000 \mathrm{mg} / \mathrm{kg}$; Group 4, topical application, $10 \mathrm{mg} / \mathrm{ml}$ ) over the 12 -week period.

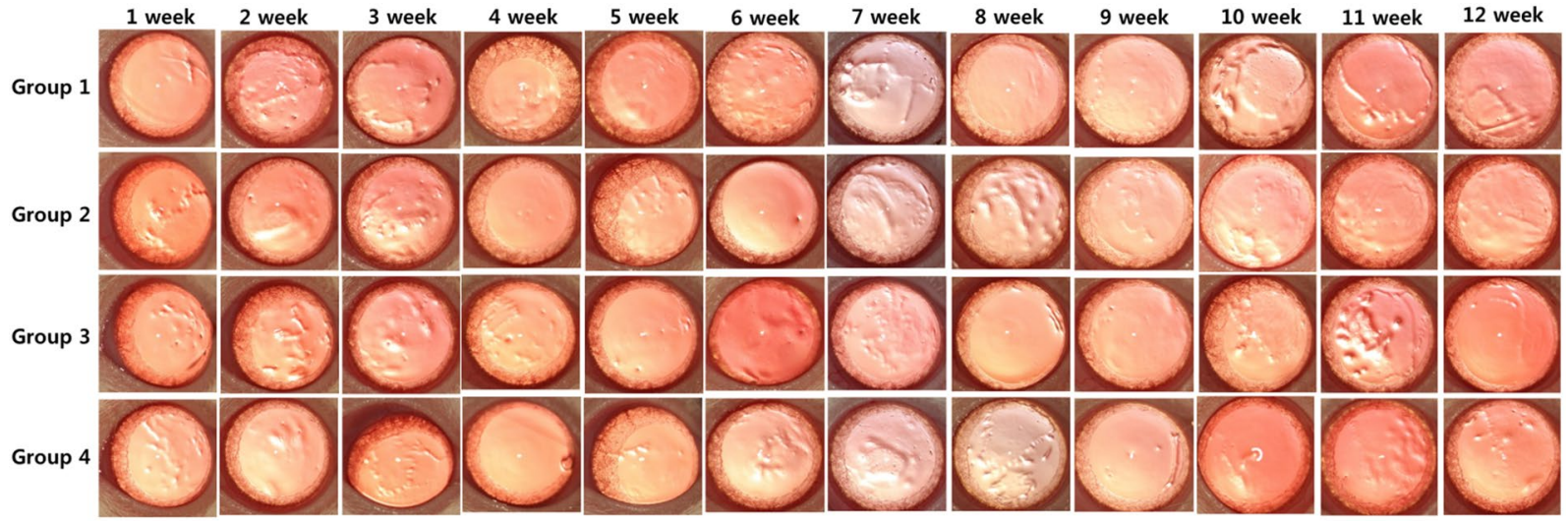

Figure 2. In vivo corneal effects of the SiNP applications. Digital photographs were obtained every week for 12 weeks. Corneal transparency and limbal vessels were normal in all the treated groups (Group 2, oral intake $100 \mathrm{mg} / \mathrm{kg}$; Group 3, oral intake $1000 \mathrm{mg} / \mathrm{kg}$; Group 4, topical application $10 \mathrm{mg} / \mathrm{ml}$ ) as compared to those of the controls (Group 1).

Ophthalmic examinations. In each group, the ocular surfaces were observed under surgical microscopic system closely each week. There was no ocular discharge, corneal opacity, or lid abnormalities in any of the groups. Digital photographs of the ocular surfaces showed no difference between the treated and control groups (Fig. 2). Corneal transparency was well maintained in all groups, with normal limbal vasculature. Fundus photographs taken monthly revealed no optic nerve or retinal abnormalities, such as hemorrhages and exudates, in either the treated or control groups (Fig. 3).

Organ weight measurements and pathological examinations. The organ weights of all the treated groups were not significantly different in comparison to those of the control group. The pathological examinations revealed no toxicological effects of the SiNPs. Figure 4 presents biopsy findings of kidney, liver, lung, spleen, and eyeballs from the SiNP-treated groups. No abnormal changes were observed in Group 2 (SiNPs, $100 \mathrm{mg} / \mathrm{kg}$ ), Group 3 (SiNPs, $1000 \mathrm{mg} / \mathrm{kg}$ ), or Group $4(10 \mathrm{mg} / \mathrm{ml}$ concentration, topical administration group), as compared to Group 1 (control).

\section{Discussion}

This 12 -week study investigated the in vivo effect of nonporous SiNPs after ocular topical administration, as well as oral intake. Based on general signs and symptoms and evaluations of target organs, including ocular tissues, small sized $(100 \mathrm{~nm})$ SiNPs induced no significant toxicity. To our knowledge, this is the first toxicity study to compare an ocular topically applied SiNP group with a control group and oral administration groups given different doses of SiNPs. 


\begin{tabular}{|c|c|c|c|c|c|c|c|c|c|c|c|c|c|c|}
\hline & & $\mathrm{WBC} \times 10^{3} / \mu l$ & $\mathrm{RBC} \times 10^{6} / \mu \mathrm{l}$ & $\begin{array}{l}\text { HGB g/ } \\
\text { dL }\end{array}$ & НCT \% & MCV fL & \begin{tabular}{|l|} 
MCH \\
pg
\end{tabular} & $\begin{array}{l}\text { MCHC } \\
\mathrm{g} / \mathrm{dL}\end{array}$ & $\begin{array}{l}\text { RDW } \\
\%\end{array}$ & $\begin{array}{l}\text { HDW } \\
\text { g/dL }\end{array}$ & PLT $\times 10^{3} / \mu l$ & MPV fL & PDW \% & $\begin{array}{l}\text { PCT } \\
\%\end{array}$ \\
\hline \multirow{3}{*}{ G1 } & Mean & 7.52 & 7.99 & 14.4 & 47.3 & 59.3 & 18.1 & 30.5 & 12.64 & 2.27 & 995 & 8.68 & 48.64 & 0.86 \\
\hline & SD & 3.75 & 0.66 & 0.9 & 4.1 & 2.5 & 0.7 & 0.9 & 0.66 & 0.20 & 110 & 0.42 & 1.91 & 0.09 \\
\hline & $\mathrm{N}$ & 10 & 10 & 10 & 10 & 10 & 10 & 10 & 10 & 10 & 10 & 10 & 10 & 10 \\
\hline \multirow{3}{*}{ G2 } & Mean & 5.69 & 7.97 & 14.3 & 46.5 & 58.5 & 18.1 & 30.9 & 12.38 & 2.17 & 943 & 8.21 & 48.44 & 0.78 \\
\hline & SD & 1.99 & 0.54 & 0.4 & 2.3 & 2.1 & 0.9 & 0.9 & 0.46 & 0.15 & 100 & 0.55 & 1.46 & 0.12 \\
\hline & $\mathrm{N}$ & 10 & 10 & 10 & 10 & 10 & 10 & 10 & 10 & 10 & 10 & 10 & 10 & 10 \\
\hline \multirow{3}{*}{ G3 } & Mean & 5.61 & 8.01 & 14.6 & 47.1 & 58.9 & 18.2 & 30.9 & 12.61 & 2.23 & 907 & 8.50 & 49.74 & 0.77 \\
\hline & SD & 2.18 & 0.62 & 0.6 & 3.0 & 2.5 & 0.8 & 0.8 & 0.41 & 0.13 & 88 & 0.50 & 1.15 & 0.11 \\
\hline & $\mathrm{N}$ & 10 & 10 & 10 & 10 & 10 & 10 & 10 & 10 & 10 & 10 & 10 & 10 & 10 \\
\hline \multirow{3}{*}{ G4 } & Mean & 5.87 & 7.92 & 14.5 & 46.3 & 58.6 & 18.3 & 31.2 & 12.58 & 2.24 & 837 & 8.64 & 49.77 & \begin{tabular}{|l}
0.73 \\
\end{tabular} \\
\hline & SD & 2.49 & 0.48 & 0.8 & 2.3 & 3.0 & \begin{tabular}{|l|}
0.9 \\
\end{tabular} & 0.8 & 0.44 & \begin{tabular}{|l|l|}
0.15 \\
\end{tabular} & 105 & 0.49 & 2.16 & \begin{tabular}{|l|l|}
0.12 \\
\end{tabular} \\
\hline & $\mathrm{N}$ & 10 & 10 & 10 & 10 & 10 & 10 & 10 & 10 & 10 & \begin{tabular}{|l|}
10 \\
\end{tabular} & 10 & 10 & \begin{tabular}{|l|}
10 \\
\end{tabular} \\
\hline
\end{tabular}

Table 3. Hematologic findings at 12 weeks (1). G: group, SD: standard deviation, N: number, WBC: white blood cells, RBC: red blood cells, HGB: hemoglobin, HCT: hematocrit, MCV: mean corpuscular volume, $\mathrm{MCH}$ : mean corpuscular hemoglobin, MCHC: mean cell hemoglobin concentration, RDW: red cell distribution width, HDW: hemoglobin distribution width, PLT: platelets, MPV: mean platelet volume, PDW: platelet distribution width, PCT: plateletcrit.

\begin{tabular}{|c|c|c|c|c|c|c|c|c|c|c|c|c|c|c|c|}
\hline & & $\begin{array}{l}\text { Neu } \\
\%\end{array}$ & $\begin{array}{l}\text { Lym } \\
\%\end{array}$ & $\begin{array}{l}\text { Mono } \\
\%\end{array}$ & $\begin{array}{l}\text { Eos } \\
\%\end{array}$ & $\begin{array}{l}\text { Baso } \\
\%\end{array}$ & $\begin{array}{l}\text { Luc } \\
\%\end{array}$ & Neu $\times 10^{3} / \mu l$ & $\operatorname{Lym} \times 10^{3} / \mu l$ & Mono $\times 10^{3} / \mu l$ & $\operatorname{Eos} \times 10^{3} / \mu l$ & Baso $\times 10^{3} / \mu l$ & Luc $\times 10^{3} / \mu l$ & $\begin{array}{l}\text { Reti } \\
\%\end{array}$ & Reti $\times 10^{9} / \mathrm{L}$ \\
\hline \multirow{3}{*}{ G1 } & Mean & 15.9 & 77.9 & 3.2 & 1.4 & 0.2 & 1.3 & 0.87 & 4.48 & 0.18 & 0.08 & 0.01 & 0.07 & 2.33 & 184.59 \\
\hline & SD & 4.3 & 5.2 & 1.3 & 0.6 & 0.1 & 0.6 & 0.32 & 1.68 & 0.08 & 0.04 & 0.01 & 0.03 & 0.40 & 29.75 \\
\hline & $\mathrm{N}$ & 10 & 10 & 10 & 10 & 10 & 10 & 10 & 10 & 10 & 10 & 10 & 10 & 10 & 10 \\
\hline \multirow{3}{*}{ G2 } & Mean & 14.4 & 80.6 & 2.5 & 1.3 & 0.2 & 1.1 & 0.78 & 4.55 & 0.14 & 0.07 & 0.01 & 0.06 & 2.47 & 196.27 \\
\hline & SD & 2.6 & 3.1 & 0.8 & 0.4 & 0.1 & 0.2 & 0.26 & 1.84 & 0.08 & 0.03 & 0.01 & 0.02 & 0.39 & 22.60 \\
\hline & $\mathrm{N}$ & 10 & 10 & 10 & 10 & 10 & 10 & 10 & 10 & 10 & 10 & 10 & 10 & 10 & 10 \\
\hline \multirow{3}{*}{ G3 } & Mean & 14.7 & 80.6 & 2.4 & 1.1 & 0.2 & 1.0 & 0.86 & 4.71 & 0.15 & 0.07 & 0.02 & 0.06 & 2.37 & 186.81 \\
\hline & SD & 4.4 & 4.7 & 0.7 & 0.7 & 0.1 & 0.6 & 0.42 & 1.94 & 0.09 & 0.04 & 0.02 & 0.05 & 0.55 & 38.16 \\
\hline & $\mathrm{N}$ & 10 & 10 & 10 & 10 & 10 & 10 & 10 & 10 & 10 & 10 & 10 & 10 & 10 & 10 \\
\hline \multirow{3}{*}{ G4 } & Mean & 16.5 & 78.0 & 2.8 & 1.5 & 0.3 & 1.0 & 1.23 & 5.84 & 0.23 & 0.12 & 0.02 & 0.08 & 2.28 & 180.48 \\
\hline & SD & 6.6 & 7.0 & 0.9 & 0.8 & 0.2 & 0.3 & 0.84 & 2.92 & 0.17 & 0.11 & 0.02 & 0.05 & 0.61 & 40.91 \\
\hline & $\mathrm{N}$ & 10 & 10 & 10 & 10 & 10 & 10 & 10 & 10 & 10 & 10 & 10 & 10 & 10 & 10 \\
\hline
\end{tabular}

Table 4. Hematologic findings at 12 weeks (2). G: group, SD: standard deviation, N: number, Neu: neutrophils, Lym: lymphocytes, Mono: monocytes, Eos: eosinophils, Baso: basophils, Luc: large unstained cells, Reti: reticulocytes.

Daily human intake of silica nanoparticles from food is estimated to be $1.8 \mathrm{mg} / \mathrm{kg}$ according to a previous study ${ }^{21}$. When considering the initial body weight of the rats (approximately $200 \mathrm{~g}$ ), our topical administration of SiNPs was equivalent to a daily application of $13.3 \mathrm{mg} / \mathrm{kg}$ onto the ocular surface. This is about 7.4 times higher than the estimated normal daily human oral exposure. In addition, we previously reported the an in vitro safety level of $100 \mu \mathrm{g} / \mathrm{ml}$ concentration of SiNPs onto cultured corneal epithelial cells ${ }^{19}$. The concentration tested in the current in vivo experiment $(10 \mathrm{mg} / \mathrm{ml})$ is 100 times higher than the verified safe concentration $(100 \mu \mathrm{g} / \mathrm{ml})$ for cell cultures. It is known that only $1 \%$ or less of topical medication reaches the target intraocular structure because of tear clearance and systemic absorption via conjunctival vessels ${ }^{22}$. This is why we selected the $10 \mathrm{mg} / \mathrm{ml} \mathrm{con-}$ centration of SiNP solution as the testing concentration. Our low and high doses of oral SiNPs are equivalent to daily exposures of $12.6 \mathrm{mg} / \mathrm{kg}$ and $126 \mathrm{mg} / \mathrm{kg}$ of SiNPs for one week. These are about 7 and 70 times higher than the estimated normal daily oral exposure in humans, respectively. Therefore, we consider our tested doses were high enough to reveal any toxicity of SiNPs that could be induced by ocular topical or oral applications as possible future drug delivery platforms.

Our results revealed no signs of acute or subchronic toxicity in the low-dose or high-dose oral intake SiNP groups. Furthermore, the high-dose $(1000 \mathrm{mg} / \mathrm{kg})$ treatment had no effects on body weights and food/water consumption. Lee et al. ${ }^{23}$ reported that kidneys, liver, lungs, and spleen were target organs of colloidal SiNPs ( $20 \mathrm{~nm}$ and $100 \mathrm{~nm}$ ) administered via the oral route in rats. In the present study, the histopathological examinations revealed no target organ damage. In addition, the organ weights of the different groups were not significantly different. Although the hematologic and biochemical parameters of the groups varied slightly, these variations did not seem to have any particular significance. Together, these data suggested that oral treatment with nonporous SiNPs exerted no toxicity when administered at doses up to $1000 \mathrm{mg} / \mathrm{kg}$ for one week. 


\begin{tabular}{|c|c|c|c|c|c|c|c|c|c|c|c|c|c|c|c|c|c|c|c|c|c|}
\hline & & $\begin{array}{l}\text { AST } \\
\text { U/L }\end{array}$ & $\begin{array}{l}\text { ALT } \\
\text { U/L }\end{array}$ & $\begin{array}{l}\text { ALP } \\
\text { U/L }\end{array}$ & $\begin{array}{l}\text { GGT } \\
\text { U/L }\end{array}$ & $\begin{array}{l}\text { LDH } \\
\text { U/L }\end{array}$ & $\begin{array}{l}\text { TBil } \\
\text { mg/ } \\
\text { dL }\end{array}$ & $\begin{array}{l}\text { DBil } \\
\text { mg/ } \\
\text { dL }\end{array}$ & $\begin{array}{l}\text { TPRO } \\
\mathrm{g} / \mathrm{dL}\end{array}$ & $\begin{array}{l}\text { ALB } \\
\text { g/ } \\
\text { dL }\end{array}$ & $\begin{array}{l}\text { BUN } \\
\text { mg/ } \\
\text { dL }\end{array}$ & $\begin{array}{l}\text { CREA } \\
\mathrm{mg} / \\
\mathrm{dL}\end{array}$ & $\begin{array}{l}\text { TCHO } \\
\mathrm{mg} / \\
\mathrm{dL}\end{array}$ & $\begin{array}{l}\text { TG } \\
\text { mg/ } \\
\text { dL }\end{array}$ & $\begin{array}{l}\text { HDLC } \\
\mathrm{mg} / \\
\mathrm{dL}\end{array}$ & \begin{tabular}{|l|} 
LDLC \\
$\mathrm{mg} /$ \\
$\mathrm{dL}$
\end{tabular} & $\begin{array}{l}\text { GLU } \\
\text { mg/ } \\
\text { dL }\end{array}$ & $\begin{array}{l}\mathrm{Na} \\
\mathrm{mmol} / \\
\mathrm{L}\end{array}$ & $\begin{array}{l}\mathbf{K} \\
\mathbf{~ m m o l} / \\
\mathbf{L}\end{array}$ & $\begin{array}{l}\mathrm{Cl} \\
\mathrm{mmol} / \mathrm{l} \\
\mathrm{L}\end{array}$ & $\begin{array}{l}\text { CK } \\
\text { U/L }\end{array}$ \\
\hline \multirow{3}{*}{ G1 } & Mean & 129.09 & 58.37 & 316.28 & 5.69 & 409.87 & 0.14 & 0.13 & & & 15.62 & & 83.26 & 73.76 & 69.77 & 18.46 & 262.88 & 142.18 & \begin{tabular}{|l|}
4.25 \\
\end{tabular} & 102.61 & 116.50 \\
\hline & SD & 38.94 & 10.56 & 9.86 & 1.15 & 146.47 & 0.03 & 0.02 & & & 1.40 & 04 & 2.23 & 38.25 & 10.03 & 4.65 & 86.98 & 2.05 & 1.05 & 1.60 & 25.98 \\
\hline & $\mathrm{N}$ & .00 & 10.00 & .00 & & & .00 & 10.00 & & & 10.00 & & & & 0.00 & & & & & & .00 \\
\hline \multirow{3}{*}{ G2 } & Mean & 2.65 & 52.10 & 90.40 & 4.83 & & & & & & & & & & & & & 44.43 & & & 86.60 \\
\hline & SD & 23.31 & \begin{tabular}{|l|}
7.08 \\
\end{tabular} & 67.16 & 0.45 & 97.29 & 0.02 & 0.02 & 0.43 & 0.22 & 2.29 & 0.03 & 13.91 & 21.55 & 5.87 & 3.94 & \begin{tabular}{|l|}
19.70 \\
\end{tabular} & 0.94 & 0.68 & 1.50 & 31.05 \\
\hline & $\mathrm{N}$ & 10.00 & 10.00 & 10.00 & 10.00 & 0.00 & 10.00 & 10.00 & 0.00 & 10.00 & 10.00 & 10.00 & 10.00 & 10.00 & 10.00 & 10.00 & 10.00 & 0.00 & 10.00 & 10.00 & 10.00 \\
\hline \multirow{3}{*}{ G3 } & Mean & 119.01 & \begin{tabular}{|l|}
50.33 \\
\end{tabular} & & & & & & & & & & & & & & & 143.72 & & & 121.63 \\
\hline & SD & 45.88 & \begin{tabular}{|l|l|}
9.64 \\
\end{tabular} & 48.59 & 0.44 & 190.07 & 0.02 & 0.01 & 0.40 & 0.16 & 2.00 & 0.02 & 677 & 24.82 & 14.42 & 4.58 & 42.30 & & & 1.03 & 38.77 \\
\hline & $\mathrm{N}$ & \begin{tabular}{|l|}
10.00 \\
\end{tabular} & 10.00 & \begin{tabular}{|l|l|}
10.00 \\
\end{tabular} & 0.00 & 200 & 10.00 & 10.00 & 0.00 & \begin{tabular}{|l|}
10.00 \\
\end{tabular} & 10.00 & 10.00 & 10.00 & 10.00 & 10.00 & 10.00 & .00 & 0.00 & 0.00 & 10.00 & 10.00 \\
\hline \multirow{3}{*}{ G4 } & Mean & 116.94 & 54.03 & 318.82 & 5.18 & 349.81 & 0.14 & \begin{tabular}{|l|l|}
0.12 \\
\end{tabular} & 6.40 & 3.23 & 19.44 & 0.37 & 90.34 & 63.95 & 71.07 & 23.02 & 240.60 & 143.59 & 3.97 & 102.88 & 105.65 \\
\hline & SD & 30.02 & 7.93 & 67.77 & 0.57 & 85.56 & 0.02 & 0.01 & 0.36 & 0.18 & 3.60 & 0.03 & 12.47 & 31.29 & 11.15 & 4.76 & 51.44 & & 0.77 & 1.18 & 18.29 \\
\hline & $\mathrm{N}$ & \begin{tabular}{|l|l|}
10.00 \\
\end{tabular} & 10.00 & \begin{tabular}{|l|}
10.00 \\
\end{tabular} & 10.00 & 10.00 & 10.00 & $\mid 10.00$ & \begin{tabular}{|l|}
10.00 \\
\end{tabular} & 10.00 & 10.00 & 10.00 & 10.00 & 10.00 & 10.00 & 10.00 & 10.00 & 10.00 & 10.00 & 10.00 & 10.00 \\
\hline
\end{tabular}

Table 5. Blood biochemical findings at 12 weeks. G: group, SD: standard deviation, N: number, AST: aspartate aminotransferase, ALT: alanine aminotransferase, ALP: alkaline phosphatase, GGT: gamma glutamyl transferase, LDH: lactate dehydrogenase, TBil: total bilirubin, DBil: direct bilirubin, TPRP: total protein, ALB: albumin, BUN: blood urea nitrogen, CREA: creatinine, TCHO: total cholesterol, TG: triglyceride, HDLC: high density lipoprotein, LDLC: low density lipoprotein, GLU: glucose, CK: creatinine kinase.

Several previous studies reported controversial results regarding the oral toxicity of SiNPs. Hassankhani et al. ${ }^{24}$ reported that oral administration of SiNPs with diameters of $10-15 \mathrm{~nm}$ resulted in significant changes in hematologic and biochemical parameters, such as albumin, cholesterol, triglyceride, total protein, urea, high-density lipoprotein, low-density lipoprotein, alkaline phosphatase, and aspartate aminotransferase activity in mice. They also demonstrated that SiNPs had toxic effects on the liver, kidneys, lungs, and testes. In contrast, Kim et al. ${ }^{25}$ reported that high-dose oral intake $(2000 \mathrm{mg} / \mathrm{kg})$ of 20 - and $100-\mathrm{nm}$ SiNPs for 90 days appeared to be relatively safe in rats. The inconsistency in the aforementioned findings on the oral toxicity of SiNPs could be explained by the results of previous studies, which found that the nanotoxicity of SiNPs was dependent on their size and dose, as well as the cell type ${ }^{13,26}$. Our current result reconfirmed the safety of oral intake of $100 \mathrm{~nm}$ sized SiNPs.

The potential toxicity of SiNPs when used as drug carriers for ophthalmic drugs is a major challenge. To resolve this issue, toxicity data on topically administered SiNPs are needed. In the present study, topical application of SiNPs did not have toxic effects on the ocular surface, retina, or optic nerve. None of the animals showed any general toxicity-related signs, such as changes in body weight, food and water consumption, or behaviors. In addition, the topical SiNPs treatment did not cause target organ toxicity, as revealed by hematologic, biochemical, and histopathological examinations. These results indicated that SiNPs could be a safe candidate platform for topical drug delivery to ocular tissues.

Recently, Jo et al. ${ }^{27}$ reported that an intravitreal injection of SiNPs produced no toxic effects on retinal neuronal cells, retinal endothelial cells, and retinal tissues in mice. In addition, they demonstrated that the SiNPs effectively inhibited anomalous retinal angiogenesis in a mouse model of oxygen-induced retinopathy. Considering that neovascularization plays a pivotal role in various ophthalmic diseases ${ }^{28-30}$, these results suggested that SiNPs could be used not only as drug carriers but also as treatment modalities for eye diseases.

The present study contains several limitations. First, we tested only one size of SiNPs. Different sizes of SiNPs could have different toxicity-related effects. Secondly, testing only one concentration $(10 \mathrm{mg} / \mathrm{ml})$ of ocular topical SiNPs may not be enough to clearly resolve the safety issues. It is possible that unexpected toxicity could be found in much higher concentrations of SiNPs. However, as shown in Supplementary Figure 1, the tested concentration $(10 \mathrm{mg} / \mathrm{ml})$ of SiNPs made the solution turbid, and a more condensed concentration could create inadequate particle dispersion for a topical agent. In addition, we did not obtain bio-distribution and excretion data in the present study. Further studies are warranted to investigate these issues.

In conclusion, in this 12-week study, both ocular topical and oral administration of nonporous SiNPs for one month was safe. These findings suggest that both oral intake and topical administration of $100 \mathrm{~nm}$-sized SiNPs are relatively safe for biomedical applications. The verification of the in vivo safety of SiNPs in the present study could be an initial step in the development of SiNPs-based topical drug delivery vehicles.

\section{Materials and Methods}

Preparation of the SiNPs. Nonporous SiNPs of $100 \mathrm{~nm}$ were prepared using the Stöber synthesis method. A detailed description of the manufacturing process of SiNPs has been reported previously ${ }^{19,20}$. To synthesize SiNPs of $100 \mathrm{~nm}, 3 \mathrm{ml}$ of ammonia $\left(\mathrm{NH}_{4} \mathrm{OH}, 28 \%\right.$, Junsei, Tokyo, Japan) and $50 \mathrm{ml}$ of ethyl alcohol (EtOH, anhydrous, 99.5\%, Daejung, Kyeonggi, Korea) were first mixed. Then, $1.5 \mathrm{ml}$ of tetraethylorthosilicate (TEOS, Samchun, Kyeonggi, Korea) was quickly added while stirring the solution. Afterward, the solution was stirred for $12 \mathrm{~h}$ under ambient conditions $\left(25^{\circ} \mathrm{C}, 1 \mathrm{~atm}\right)$. The prepared SiNPs were washed three times with EtOH and centrifuged at 10,000 rpm for $15 \mathrm{~min}$ ). The final SiNP precipitates were dispersed in distilled water. 


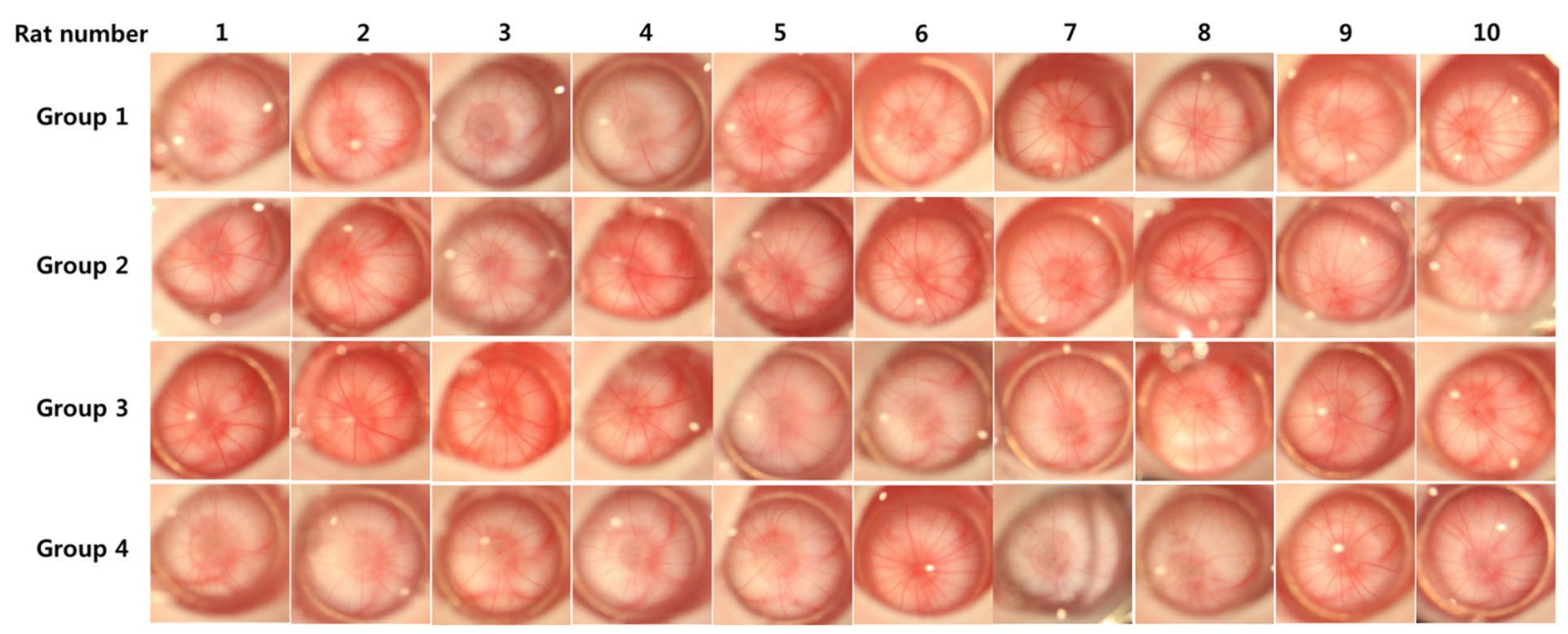

Figure 3. In vivo imaging of the optic nerve head following the SiNP applications. All the images were obtained 12 weeks after the treatments. There was no evidence of optic nerve damage or vascular changes in any of the treated groups (Group 2, oral intake $100 \mathrm{mg} / \mathrm{kg}$; Group 3, oral intake $1000 \mathrm{mg} / \mathrm{kg}$; Group 4, topical application $10 \mathrm{mg} / \mathrm{ml}$ ) compared to the controls (Group 1).
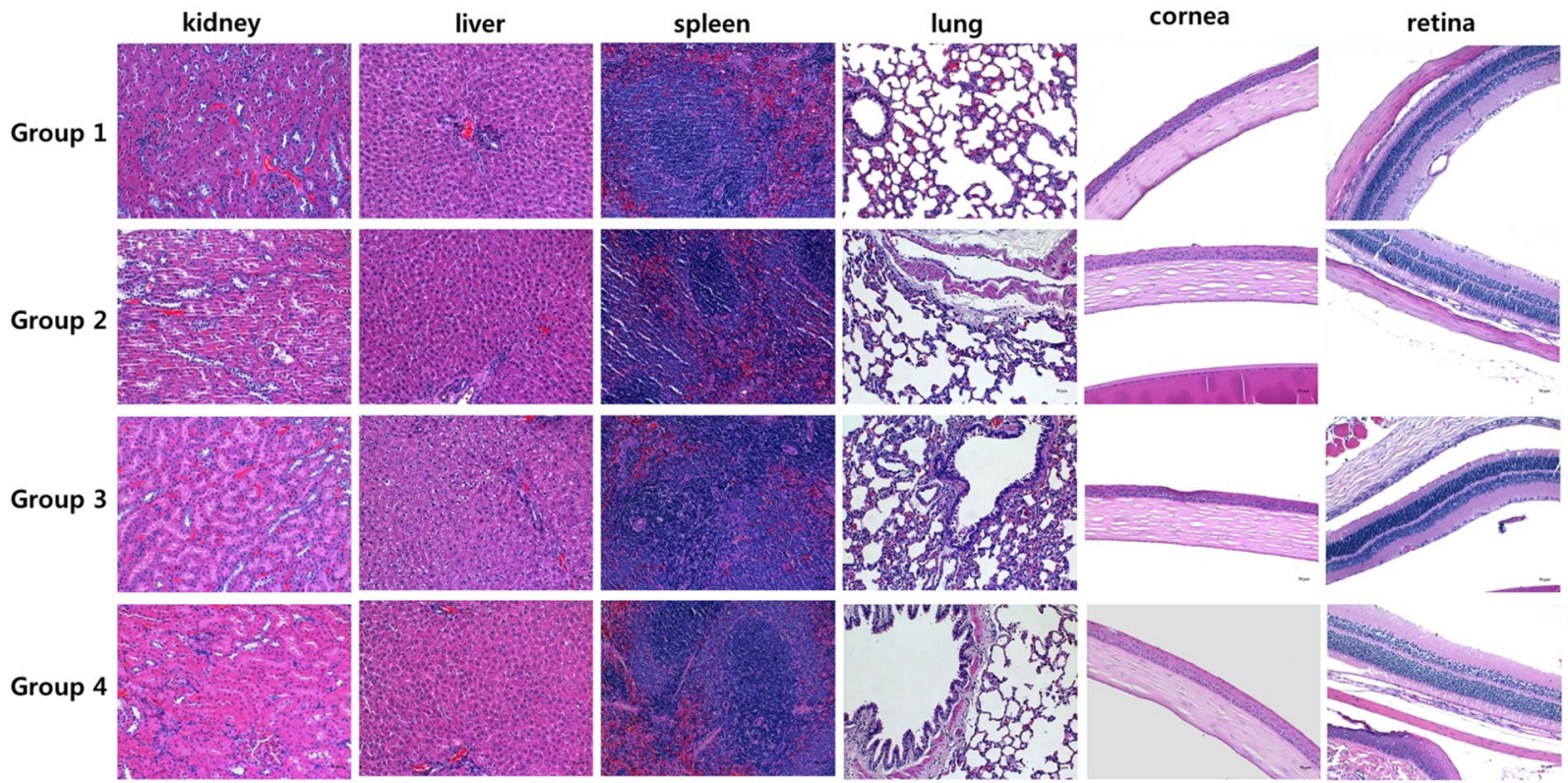

Figure 4. Histopathological findings of organs from the rats treated with SiNPs. Kidney, liver, spleen, lung, and eyeball samples were collected 12 weeks after the SiNP applications. Sections were stained with hematoxylin and eosin (×200): No treatment (Group 1, controls); low-dose oral intake (Group 2, $100 \mathrm{mg} / \mathrm{kg}$ ); high-dose oral intake (Group 3, $1000 \mathrm{mg} / \mathrm{kg}$ ); topical application (Group 4, $10 \mathrm{mg} / \mathrm{ml}$ ).

Animals. Sprague-Dawley rats (7 weeks old, 20 males and 20 females) were purchased from Koatech (Pyeongtek, Kyeonggi, Korea). The care and treatment of the animals complied with the ARVO Statement for the Use of Animals in Ophthalmic and Vision Research. The experimental protocol was approved by the Institutional Animal Care and Use Committee of Laboratory Animal Center, Osong Medical Innovation Foundation (reference number: KBIO-IACUC-2016-058).

In vivo treatment with SiNPs. The rats in Group 1 received no treatment and served as the control. Groups 2 and 3 were treated with SiNPs (a total of $100 \mathrm{mg} / \mathrm{kg}$ and $1000 \mathrm{mg} / \mathrm{kg}$, respectively) via the oral route. The SiNPs were mixed with food and administered for one week. In Group 4, the SiNPs were administered via a topical route (one drop of $10 \mathrm{mg} / \mathrm{ml}$ concentration diluted in phosphate buffered saline applied to right eyes four times a day for one month). All the rats were observed for 12 weeks. 
Clinical observations. Body weight and food and water intake were measured weekly. All signs of general toxicity were monitored daily.

Hematology and biochemical tests. Blood samples were taken monthly from the carotid vein after anesthesia induced by isoflurane. The animals fasted for $12 \mathrm{~h}$ prior to the blood sampling. The hematologic measurements consisted of the blood cell count (white blood cells, red blood cells, and platelets), as well as hemoglobin and hematocrit values, differential count of white blood cells (neutrophils, lymphocytes, monocytes, eosinophils, and basophils), reticulocytes, mean corpuscular volume, mean corpuscular hemoglobin, mean cell hemoglobin concentration, red cell distribution width, and hemoglobin distribution width. The biochemical measurements consisted of analyses of the following: glucose, total protein, total cholesterol, triglyceride, low-density lipoprotein cholesterol, high-density lipoprotein cholesterol, alkaline phosphatase, alanine aminotransferase, aspartate aminotransferase, GGT, total bilirubin, direct bilirubin, blood urea nitrogen, creatinine, lactate dehydrogenase, creatinine kinase, and electrolytes (sodium, potassium, and chloride).

Ophthalmic examination. In each group, the ocular surfaces were closely observed using surgical microscopic system (OPMI ${ }^{\circledR}$ Pico Surgical Microscope; Carl Zeiss, Oberkochen, Germany) each week. Any ocular discharge, opacity, or lid abnormalities were recorded. Digital pictures of the ocular surfaces were taken weekly using a surgical microscopic system. Fundus pictures were taken monthly using a surgical microscope and ocular contact lens system (G-4 gonio lens, Volk, Mentor, OH).

Organ weight measurements and pathological examinations. At the end of the experiment, the animals were sacrificed, and their organs (brain, liver, lung, spleen, heart, kidneys [bilateral], intestine, eyeballs [bilateral], ovaries, or testes [bilateral]) were harvested. Close observation of any abnormal findings in all orifices, orbit, thorax, abdomen and cranial cavity was performed. Any signs of gross abnormalities were recorded. The weight of each harvested organ was measured as an absolute (organ itself) and relative (organ weight divided by body weight) value. The testes were fixed in Bouin's solution, and the eyeballs were fixed in Davidson's solution. The other organs were fixed with $10 \%$ neutral buffered formalin. The histologic examination was performed after hematoxylin and eosin staining.

Statistical analysis. Data are presented as means \pm standard deviation. Data on body weights, food and water intakes, hematologic parameters, biochemical parameters, and organ weights were evaluated by the Student's $t$-test and an analysis of variance. The data were analyzed by SPSS (version 12.0; SPSS Inc., Chicago, IL, USA). Differences were considered statistically significant when $P$-values were less than 0.05 .

\section{References}

1. Napierska, D., Thomassen, L. C., Lison, D., Martens, J. A. \& Hoet, P. H. The nanosilica hazard: another variable entity. Particle and fibre toxicology 7, 39, doi:10.1186/1743-8977-7-39 (2010).

2. Molokhia, S. A., Thomas, S. C., Garff, K. J., Mandell, K. J. \& Wirostko, B. M. Anterior eye segment drug delivery systems: current treatments and future challenges. Journal of ocular pharmacology and therapeutics: the official journal of the Association for Ocular Pharmacology and Therapeutics 29, 92-105, doi:10.1089/jop.2012.0241 (2013).

3. Liu, S., Jones, L. \& Gu, F. X. Nanomaterials for ocular drug delivery. Macromolecular bioscience 12, 608-620, doi:10.1002/ mabi.201100419 (2012)

4. Sharma, O. P., Patel, V. \& Mehta, T. Nanocrystal for ocular drug delivery: hope or hype. Drug delivery and translational research. doi:10.1007/s13346-016-0292-0 (2016).

5. Verma, P. \& Ahuja, M. Cubic liquid crystalline nanoparticles: optimization and evaluation for ocular delivery of tropicamide. Drug delivery, 1-12, doi:10.3109/10717544.2016.1143057 (2016).

6. Taketani, Y. et al. Topical Use of Angiopoietin-like Protein 2 RNAi-loaded Lipid Nanoparticles Suppresses Corneal Neovascularization. Molecular therapy. Nucleic acids 5, e292, doi:10.1038/mtna.2016.1 (2016).

7. Tandon, A. et al. BMP7 gene transfer via gold nanoparticles into stroma inhibits corneal fibrosis in vivo. PloS one 8, e66434, doi:10.1371/journal.pone.0066434 (2013).

8. Jani, P. D. et al. Nanoparticles sustain expression of Flt intraceptors in the cornea and inhibit injury-induced corneal angiogenesis. Investigative ophthalmology \& visual science 48, 2030-2036, doi:10.1167/iovs.06-0853 (2007).

9. Contreras-Ruiz, L. et al. Ocular tolerance to a topical formulation of hyaluronic acid and chitosan-based nanoparticles. Cornea 29, 550-558, doi:10.1097/ICO.0b013e3181bd9eee (2010).

10. Jumelle, C. et al. Delivery of macromolecules into the endothelium of whole ex vivo human cornea by femtosecond laser-activated carbon nanoparticles. The British journal of ophthalmology. doi:10.1136/bjophthalmol-2015-307610 (2016).

11. Kompella, U. B., Amrite, A. C., Pacha Ravi, R. \& Durazo, S. A. Nanomedicines for back of the eye drug delivery, gene delivery, and imaging. Progress in retinal and eye research 36, 172-198, doi:10.1016/j.preteyeres.2013.04.001 (2013).

12. Napierska, D. et al. Size-dependent cytotoxicity of monodisperse silica nanoparticles in human endothelial cells. Small 5, 846-853, doi:10.1002/smll.200800461 (2009).

13. Kim, I. Y., Joachim, E., Choi, H. \& Kim, K. Toxicity of silica nanoparticles depends on size, dose, and cell type. Nanomedicine 11, 1407-1416, doi:10.1016/j.nano.2015.03.004 (2015).

14. Berg, J. M., Romoser, A. A., Figueroa, D. E., Spencer West, C. \& Sayes, C. M. Comparative cytological responses of lung epithelial and pleural mesothelial cells following in vitro exposure to nanoscale SiO2. Toxicol In Vitro 27, 24-33, doi:10.1016/j.tiv.2012.09.002 (2013).

15. Gilardino, A. et al. Interaction of $\mathrm{SiO} 2$ nanoparticles with neuronal cells: Ionic mechanisms involved in the perturbation of calcium homeostasis. Int J Biochem Cell Biol 66, 101-111, doi:10.1016/j.biocel.2015.07.012 (2015).

16. Sergent, J. A., Paget, V. \& Chevillard, S. Toxicity and genotoxicity of nano-SiO2 on human epithelial intestinal HT-29 cell line. Ann Occup Hyg 56, 622-630, doi:10.1093/annhyg/mes005 (2012).

17. Ryu, H. J. et al. Evaluation of silica nanoparticle toxicity after topical exposure for 90 days. Int J Nanomedicine 9(Suppl 2), 127-136, doi:10.2147/IJN.S57929 (2014).

18. Setyawati, M. I., Tay, C. Y. \& Leong, D. T. Mechanistic Investigation of the Biological Effects of $\mathrm{SiO}(2)$, TiO(2), and ZnO Nanoparticles on Intestinal Cells. Small 11,3458-3468, doi:10.1002/smll.201403232 (2015).

19. Park, J. H. et al. The Effect of Silica Nanoparticles on Human Corneal Epithelial Cells. Scientific reports 6, 37762, doi:10.1038/ srep37762 (2016) 
20. Yim, B. et al. The Effects of Nonporous Silica Nanoparticles on Cultured Human Keratocytes. Invest Ophthalmol Vis Sci 58, 362-371, doi:10.1167/iovs.16-20603 (2017).

21. van der Zande, M. et al. Sub-chronic toxicity study in rats orally exposed to nanostructured silica. Particle and fibre toxicology 11, 8 , doi:10.1186/1743-8977-11-8 (2014)

22. Morrison, P. W. \& Khutoryanskiy, V. V. Advances in ophthalmic drug delivery. Therapeutic delivery 5, 1297-1315, doi:10.4155/ tde.14.75 (2014).

23. Lee, J. A. et al. Tissue distribution and excretion kinetics of orally administered silica nanoparticles in rats. Int J Nanomedicine 9(Suppl 2), 251-260, doi:10.2147/IJN.S57939 (2014).

24. Hassankhani, R. et al. In vivo toxicity of orally administrated silicon dioxide nanoparticles in healthy adult mice. Environ Sci Pollut Res Int 22, 1127-1132, doi:10.1007/s11356-014-3413-7 (2015).

25. Kim, Y. R. et al. Toxicity of colloidal silica nanoparticles administered orally for 90 days in rats. Int J Nanomedicine 9 (Suppl 2), 67-78, doi:10.2147/IJN.S57925 (2014).

26. Lee, S., Yun, H. S. \& Kim, S. H. The comparative effects of mesoporous silica nanoparticles and colloidal silica on inflammation and apoptosis. Biomaterials 32, 9434-9443, doi:10.1016/j.biomaterials.2011.08.042 (2011).

27. Jo, D. H., Kim, J. H., Yu, Y. S., Lee, T. G. \& Kim, J. H. Antiangiogenic effect of silicate nanoparticle on retinal neovascularization induced by vascular endothelial growth factor. Nanomedicine 8, 784-791, doi:10.1016/j.nano.2011.09.003 (2012).

28. Crawford, T. N., Alfaro, D. V. 3rd, Kerrison, J. B. \& Jablon, E. P. Diabetic retinopathy and angiogenesis. Curr Diabetes Rev 5, 8-13 (2009).

29. Witmer, A. N., Vrensen, G. F., Van Noorden, C. J. \& Schlingemann, R. O. Vascular endothelial growth factors and angiogenesis in eye disease. Prog Retin Eye Res 22, 1-29 (2003).

30. Kim, M. et al. Angiogenesis in glaucoma filtration surgery and neovascular glaucoma: A review. Surv Ophthalmol 60, 524-535, doi:10.1016/j.survophthal.2015.04.003 (2015).

\section{Acknowledgements}

This study was supported by a grant from the Korea Health Technology R\&D Project through the Korea Health Industry Development Institute, funded by the Ministry of Health and Welfare, Republic of Korea (grant number: HI-15C1653). It was also supported by the Basic Science Research Program through the National Research Foundation of Korea, funded by the Ministry of Education (grant number: 2016R1D1A1B03931724).

\section{Author Contributions}

M.K., J.H.P., J.H., and C.Y.P. designed the experiment. M.K., H.J., J.H., and C.Y.P. wrote the main manuscript text. M.K., H.J., and J.H.P. prepared Figure. 1 and Tables 1-3. J.H.P., W.S.C., and B.H.L. prepared Fig $2-4$ and Tables 4-5. M.K. and C.Y.P. corrected and proofread the manuscript. All the authors reviewed the manuscript.

\section{Additional Information}

Supplementary information accompanies this paper at doi:10.1038/s41598-017-08843-9

Competing Interests: The authors declare that they have no competing interests.

Publisher's note: Springer Nature remains neutral with regard to jurisdictional claims in published maps and institutional affiliations.

(c) (i) Open Access This article is licensed under a Creative Commons Attribution 4.0 International

License, which permits use, sharing, adaptation, distribution and reproduction in any medium or format, as long as you give appropriate credit to the original author(s) and the source, provide a link to the Creative Commons license, and indicate if changes were made. The images or other third party material in this article are included in the article's Creative Commons license, unless indicated otherwise in a credit line to the material. If material is not included in the article's Creative Commons license and your intended use is not permitted by statutory regulation or exceeds the permitted use, you will need to obtain permission directly from the copyright holder. To view a copy of this license, visit http://creativecommons.org/licenses/by/4.0/.

(C) The Author(s) 2017 